\title{
A COMPARATIVE TAXONOMIC STUDY ON TWO FORMS OF CANDIDA PARAPSILOSIS (ASHFORd) LANGERON ET TALICE
}

\author{
TAKASHI NAKASE, KAZUO KOMAGATA,* \\ AND YOSHIMURA FUKAZAWA** \\ Central Research Laboratories, Ajinomoto Co., Inc., Kawasaki 210, \\ *Institute of Applied Microbiology, University of Tokyo, Tokyo 113, and \\ **Department of Microbiology, Meiji College of Pharmacy, Tokyo 154
}

(Received July 25, 1979)

\begin{abstract}
A comparative study was made on two forms of Candida parapsilosis. From the reciprocal absorption experiment of antiserum for heated cells of these yeasts, and gel diffusion precipitation of mannans, the two forms were assumed to possess a small amount of respectively specific antigens in addition to antigens common to both. Factor antiserum 24 prepared from antiserum for Saccharomyces rosei agglutinated $C$. parapsilosis form I but not form II, and is considered to be useful for clear-cut discrimination of the two forms. Proton magnetic resonance spectrum of mannans also demonstrated the difference of the two forms. Further, C. parapsilosis assimilated L-arabinose, did not excrete excess amount of riboflavin into synthetic media, and did not require thiamine. Since $C$. parapsilosis form II was found to correspond to the imperfect form of Lodderomyces elongisporus, these characteristics are useful for the discrimination of the imperfect form of L. elongisporus from C. parapsilosis.
\end{abstract}

In 1962, two isolates of asporogenous yeast were obtained from adhesives of a neutralizing tank of L-glutamic acid in monosodium glutamate manufacturing plant, and were identified with Candida parapsilosis (1). Later, these two yeasts were found to differ from typical strains of $C$. parapsilosis in the lack of assimilation of L-arabinose, requirement of thiamine, excretion of excess amount of riboflavin, and serological characteristics. One of the authors tentatively dealt with these atypical strains as $C$. parapsilosis form II, and typical strains of $C$. parapsilosis as form I (2).

A precise study was carried out to clarify the taxonomic situation of yeasts belonging to $C$. parapsilosis form II, and these were found to represent the imperfect form of Lodderomyces elongisporus.

In the Second Edition of "The Yeasts, a Taxonomic Study" published in 1970, 
C. parapsilosis was regarded as the imperfect form of Lodderomyces elongisporus(3). However, MeYer and Phaff (4) reported that these two species were not closely related in DNA-DNA hybridization study.

In the present work, we found that $C$. parapsilosis can be discriminated from L. elongisporus and its imperfect form by assimilation of L-arabinose, requirement of thiamine, lack of antigen 24, proton NMR spectrum of mannan, and lack of excretion of excess amount of riboflavin into synthetic media. These characteristics are useful for routine discrimination of the imperfect form of L. elongisporus from C. parapsilosis.

\section{MATERIALS AND METHODS}

Microorganisms. Twenty strains of $C$. parapsilosis form I, two strains of $C$. parapsilosis form II, and a strain of L. elongisporus were employed. Source of strains is listed in Table 1. In addition to these strains, Candida albicans J-1012 (serotype A) and J-1445 (serotype B), C. stellatoidea J-1016, C. guilliermondii J-1023, C. krusei J-1005, C. pseudotropicals J-1004, Torulopsis glabrata J-4002, and Saccharomyces rosei $\mathrm{J}-6013$ were used for serological investigation.

Taxonomic characteristics conventionally employed. Taxonomic characteristics were investigated mainly by the method described by WICKERHAM (5) and by those described in the Second Edition of "The Yeasts, a Taxonomic Study" (6). Vitamin requirement and maximum growth temperature were determined by the methods previously described (7).

Extraction and purification of polysaccharides. The yeast cells grown for $48 \mathrm{hr}$ with gentle shaking in yeast extract $(0.3 \%)$-malt extract $(0.3 \%)$-peptone $(0.5 \%)$ broth supplemented with $3 \%$ of glucose were harvested by centrifugation and washed three times with distilled water. The washed cell debris was suspended in 5 volumes of $2 \%$ aqueous patassium hydroxide solution and extracted for $2 \mathrm{hr}$ at $100^{\circ}$. After neutralization with acetic acid, the extract was centrifuged and crude polysaccharide was recovered by the addition of 2 volumes of methanol into the resultant supernatant. The polysaccharide was purified via copper complex as described by GoRIN and SPENCER (8).

Determination of component sugars of polysaccharide. Polysaccharide was analyzed for its component sugars by thin-layer chromatography using silica gel plate Art. 5721 (Merck, Germany) after being hydrolyzed in $1 \mathrm{~N}_{2} \mathrm{SO}_{4}\left(100^{\circ}, 18 \mathrm{hr}\right.$ ) and neutralized with saturated $\mathrm{Ba}(\mathrm{OH})_{2}$. Ethyl acetate-isopropanol-water (65:22:11) was used as the solvent system for development. The sugars were detected with $p$-anisaldehyde-sulfuric acid.

Determination of proton NMR spectrum. The proton NMR spectrum of polysaccharide was determined in $20 \%$ solution of $\mathrm{D}_{2} \mathrm{O}$ at $70^{\circ}$, using a JEOL nuclear magnetic resonance spectrometer at $100 \mathrm{MHz}$. Sodium 3-(trimethylsilyl)propanesulfonate (DSS) was used as the internal standard. 
Table 1. Strains employed.

\begin{tabular}{|c|c|c|c|c|}
\hline \multicolumn{2}{|c|}{ Strains } & \multicolumn{3}{|c|}{ Sources } \\
\hline \multirow{20}{*}{$\begin{array}{l}\text { C. parapsilosis } \\
\text { form I }\end{array}$} & J-1006 & \multicolumn{3}{|l|}{ NI 7493} \\
\hline & $\mathbf{J}-1015$ & \multicolumn{3}{|c|}{ ATCC 10232} \\
\hline & J-1025 & \multicolumn{3}{|c|}{ ATCC 10322} \\
\hline & J-1104 & \multicolumn{3}{|c|}{ IFO 0585} \\
\hline & $\mathrm{J}-1124$ & \multicolumn{3}{|l|}{ IFO 0678} \\
\hline & $\mathrm{J}-1162$ & \multicolumn{3}{|l|}{ IFO 0640} \\
\hline & $\mathrm{J}-1172$ & \multicolumn{3}{|l|}{ IFO 0708} \\
\hline & $\mathrm{J}-1481$ & \multicolumn{3}{|c|}{ CBS 604, Type } \\
\hline & AJ 4569 & \multicolumn{3}{|c|}{ IFO 0708} \\
\hline & AJ 4570 & \multicolumn{3}{|l|}{ IFO 0585} \\
\hline & AJ 4572 & \multicolumn{3}{|c|}{$\mathrm{Na}$ glutamate manufacturing factory, $\mathrm{Y}-2-2(1)$} \\
\hline & AJ 4578 & 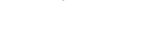 & " & $Y-2-10(1)$ \\
\hline & AJ 4583 & & $" \prime$ & $Y-3-5(1)$ \\
\hline & AJ 4588 & & $" \prime$ & $Y-4-1(1)$ \\
\hline & AJ 4597 & \multicolumn{3}{|c|}{ Kamaboko, YO-166 (16) } \\
\hline & AJ 4598 & " & YO-171 (16) & \\
\hline & AJ 4602 & \multicolumn{3}{|l|}{ NI 7542} \\
\hline & AJ 4603 & \multicolumn{3}{|l|}{ IFO 0640} \\
\hline & AJ 4604 & \multicolumn{3}{|l|}{ IFO 1068} \\
\hline & AJ 5370 & \multicolumn{3}{|c|}{ Human origin (Dr. T. Nishikawa) } \\
\hline C. parapsilosis & AJ 4571 & \multirow{2}{*}{\multicolumn{2}{|c|}{$\begin{array}{c}\mathrm{Na} \text { glutamate manufacturing factory, } \\
\text { " }\end{array}$}} & $\mathrm{Y}-2-1(1)$ \\
\hline form II & AJ 4575 & & & $\mathrm{Y}-2-6(1)$ \\
\hline L. elongisporus & AJ 5470 & \multicolumn{3}{|l|}{ CBS 2605} \\
\hline
\end{tabular}

Serological characteristics. The methods for the preparation of antisera, the slide agglutination test, and the absorption test of agglutinins followed those described by TsuchiYA et al. (9). Most of factor antisera were obtained from the Iatron Laboratory (Tokyo). Factor antiserum 24 was prepared by the authors. Gel diffusion precipitation was carried out in borate buffer ( $\mathrm{pH} 8.4)(10)$ using $0.85 \%$ of Noble agar (Difco). Undiluted antiserum was placed in the central well and $0.05 \%$ solution of purified polysaccharide was filled in the outer wells. The plate was incubated at $10^{\circ}$ for 5 days.

\section{RESULTS}

Characteristics commonly employed for determination

In the taxonomic characteristics commonly employed, strains tested in the present experiment closely resembled one another. Among 33 carbon compounds used in the assimilation test, difference was found only in one compound, L-arabinose. Twenty strains of $C$. parapsilosis form I, including the strain derived from the type (CBS 604), rapidly assimilated L-arabinose but two strains belonging to C. parapsilosis form II and L. elongisporus failed to assimilate this sugar (Table 2). 
Table 2. Physiological characteristics of C. parapsilosis and L. elongisporus (I). Assimilation of carbon compounds.

\begin{tabular}{|c|c|c|c|}
\hline \multirow[b]{2}{*}{ Carbon compounds } & \multicolumn{3}{|c|}{ Species } \\
\hline & $\begin{array}{l}\text { C. parapsilosis } \\
\text { form I } \\
\text { (20 strains) }\end{array}$ & $\begin{array}{l}\text { C. parapsilosis } \\
\text { form II } \\
\text { (2 strains) }\end{array}$ & $\begin{array}{l}\text { L. elongisporus } \\
\text { (1 strain) }\end{array}$ \\
\hline Glucose & + & + & + \\
\hline Galactose & + & + & + \\
\hline Saccharose & + & + & + \\
\hline Maltose & + & + & + \\
\hline Lactose & - & - & - \\
\hline L-Sorbose & $+, \mathrm{w},-$ & + & $\mathrm{L}$ \\
\hline Cellobiose & - & - & - \\
\hline Trehalose & + & + & + \\
\hline Melibiose & - & - & - \\
\hline Raffinose & - & - & - \\
\hline Melezitose & + & + & + \\
\hline Inulin & - & - & - \\
\hline Soluble starch & - & - & - \\
\hline D-Xylose & + & + & $\mathrm{L}$ \\
\hline L-Arabinose & + & - & - \\
\hline D-Arabinose & - & - & - \\
\hline D-Ribose & $+, w,-$ & $\mathrm{w},-$ & + \\
\hline L-Rhamnose & - & - & - \\
\hline Ethanol & + & + & + \\
\hline Glycerol & + & + & + \\
\hline Erythritol & - & - & - \\
\hline Ribitol & + & + & + \\
\hline Galactitol & - & - & - \\
\hline D-Mannitol & + & + & + \\
\hline D-Glucitol & + & + & + \\
\hline$\alpha$-Me-D-glucoside & + & + & + \\
\hline Salicin & - & - & - \\
\hline K Gluconate & + & + & + \\
\hline Ca 2-Ketogluconate & + & + & + \\
\hline DL-Lactic acid & - & - & - \\
\hline Succinic acid &,$+ w$ &,$+ w$ & + \\
\hline Citric acid & + & + & + \\
\hline Inositol & - & - & - \\
\hline
\end{tabular}

w, weak; L, latent.

All the strains used required biotin at $25^{\circ}$, and $C$. parapsilosis form II and L. elongisporus also required thiamine (Table 3 ).

Excess amount of riboflavin was excreted into the synthetic media employed for the test of carbon assimilation when C. parapsilosis form II and L. elongisporus were cultivated, while no prominent pigmentation due to riboflavin excretion was observed in the case of $C$. parapsilosis form I (Table 3). 
Table 3. Physiological characteristics of C. parapsilosis and L. elongisporus (2).

\begin{tabular}{|c|c|c|c|}
\hline \multirow[b]{2}{*}{ Characteristics } & \multicolumn{3}{|c|}{ Species } \\
\hline & $\begin{array}{c}\text { C. parapsilosis } \\
\text { form I } \\
\text { (20 strains) }\end{array}$ & $\begin{array}{c}\text { C. parapsilosis } \\
\text { form II } \\
\text { (2 strains) }\end{array}$ & $\begin{array}{l}\text { L. elongisporus } \\
\qquad \text { (1 strain) }\end{array}$ \\
\hline \multicolumn{4}{|l|}{ Fermentation } \\
\hline Glucose & + & + & + \\
\hline Galactose & V & - & - \\
\hline Saccharose & - or $\mathrm{w}$ & - & - \\
\hline Maltose & - or w & - & - \\
\hline Lactose & - & - & - \\
\hline Raffinose & - & - & - \\
\hline Melibiose & - & - & - \\
\hline Trehalose & V & $\mathrm{L}$ & $\mathbf{L}$ \\
\hline Vitamins required & biotin & $\begin{array}{l}\text { biotin, } \\
\text { thiamine }\end{array}$ & $\begin{array}{l}\text { biotin, } \\
\text { thiamine }\end{array}$ \\
\hline \multicolumn{4}{|l|}{ Maximum growth } \\
\hline temperature $\left(^{\circ}\right)$ & $40-44$ & $41-42$ & $41-42$ \\
\hline Liquefaction of gelatin & - & - & - \\
\hline Split of arbutin & - & - & - \\
\hline Production of "starch" & - & - & - \\
\hline Urease & - & - & - \\
\hline Assimilation of nitrate & - & - & - \\
\hline Production of excess & & & \\
\hline amount of riboflavin & $\cdots$ & + & + \\
\hline
\end{tabular}

+, positive; --, negative; V, variable; w, weak; L, latent.

Other characteristics including alcoholic fermentation from sugars, maximum growth temperature, splitting of arbutin, etc., were not essentially different among the strains tested (Table 3). These yeasts were also similar to one another in the morphological characteristics though development of pseudomycelium was prominent in some strains and primitive in some other strains.

\section{Serological characteristics}

Investigation of serological characteristics revealed that the yeasts employed were divided into two groups. The one is composed of strains belonging to C. parapsilosis form I and the other is C. parapsilosis form II and L. elongisporus.

Reciprocal absorption experiment of antisera with heated cells showed that some difference was present in the surface antigens of the cell envelope between the two groups (Table 4). Unabsorbed antisera for C. parapsilosis form I J-1015, C. parapsilosis form II AJ 4571, and L.elongisporus AJ 5470 intensively agglutinated the cells of all of the strains employed.

Antiserum for $C$. parapsilosis form II AJ 4571 absorbed with heated cells of C. parapsilosis form I J-1015 agglutinated cells of C. parapsilosis form II and L. elongisporus but not any of $C$. parapsilosis form I. When this antiserum was 
Table 4. Reciprocal absorption experiments among strains of $C$. parapsilosis and L. elongisporus.

\begin{tabular}{|c|c|c|c|c|}
\hline & & $\begin{array}{l}\text { L. } \\
\text { elong. }\end{array}$ & $\begin{array}{l}\text { C. parap } \\
\text { form II }\end{array}$ & C. parap. form I \\
\hline $\begin{array}{l}\text { Antisera } \\
\text { for }\end{array}$ & $\begin{array}{l}\text { Absorbed } \\
\text { with }\end{array}$ & $\begin{array}{c}\text { AJ } \\
5470\end{array}$ & 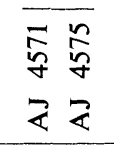 & 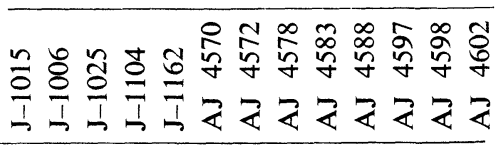 \\
\hline $\begin{array}{l}\text { C. parap. form I } \\
\mathbf{J}-1015\end{array}$ & $\begin{array}{l}\text { C. parap. form II } \\
\text { AJ } 4571\end{array}$ & - & - & ++ \pm+ \pm++++++ \pm \pm \\
\hline$n$ & L. elong. AJ 5470 & - & - - & $\pm+ \pm t \pm t+++++ \pm \pm$ \\
\hline $\begin{array}{l}\text { C. parap. form II } \\
\text { AJ } 4571\end{array}$ & C. parap. form I & + & ++ & $-\cdots-\cdots-\cdots$ \\
\hline$n$ & L. elong. AJ 5470 & - & - & $-\cdots-\cdots \cdots$ \\
\hline L. elong. AJ 5470 & C. parap. form I & + & ++ & $---\cdots--\cdots-\cdots$ \\
\hline$n$ & $\begin{array}{c}\text { C. parap. form II } \\
\text { AJ } 4571\end{array}$ & - & - - & $--\cdots-\cdots-\cdots$ \\
\hline
\end{tabular}

+ , positive agglutination; - , negative agglutination; \pm , ambiguous.

Table 5. Slide agglutination against factor antisera.

\begin{tabular}{|c|c|c|c|c|c|c|c|c|c|c|c|}
\hline \multirow{2}{*}{\multicolumn{2}{|c|}{ Heated cells }} & \multicolumn{10}{|c|}{ Slide agglutination with factor antisera ${ }^{a}$} \\
\hline & & 1 & 4 & & 6 & 8 & 9 & 13 & $13 b$ & & 34 \\
\hline \multirow{20}{*}{$\begin{array}{c}\text { C. parapsilosis } \\
\text { form I }\end{array}$} & $\mathrm{J}-1006$ & H & - & + & - & - & - & H & H & $H$ & - \\
\hline & $\mathrm{J}-1015$ & $H$ & - & + & - & - & - & $H$ & H & $H$ & - \\
\hline & $\mathrm{J}-1025$ & H & - & + & - & - & - & H & H & H & - \\
\hline & J-1104 & $\ddot{H}$ & - & \pm & - & - & - & $H$ & $H$ & $H$ & - \\
\hline & J-1124 & $\ddot{H}$ & - & + & - & - & - & H & $H$ & $H$ & - \\
\hline & $\mathrm{J}-1162$ & $H$ & - & + & - & - & - & $H$ & $H$ & $H$ & - \\
\hline & $\mathrm{J}-1172$ & H & - & \pm & - & - & - & $H$ & $H$ & $H$ & - \\
\hline & $\mathrm{J}-1481$ & $H$ & - & + & - & - & - & $H$ & $H$ & $H$ & - \\
\hline & AJ 4569 & $H$ & - & \pm & - & - & - & $H$ & $H$ & $H$ & - \\
\hline & AJ 4570 & H & - & + & - & - & - & $H$ & $H$ & $H$ & - \\
\hline & AJ 4572 & $\ddot{H}$ & - & + & - & - & - & $H$ & $H$ & $H$ & - \\
\hline & AJ 4578 & $H$ & - & + & - & - & - & $H$ & H & $H$ & - \\
\hline & AJ 4583 & $H$ & - & + & - & - & - & $H$ & $H$ & $H$ & - \\
\hline & AJ 4588 & $H$ & - & + & - & - & - & $H$ & $H$ & $\#$ & - \\
\hline & AJ 4597 & $H$ & - & + & - & - & - & $H$ & $H$ & $H$ & - \\
\hline & AJ 4598 & $H$ & - & + & - & - & - & $H$ & $H$ & $H$ & - \\
\hline & AJ 4602 & $H$ & - & + & - & - & - & $H$ & $H$ & $H$ & - \\
\hline & AJ 4603 & H & - & \pm & - & - & - & H & $H$ & $H$ & - \\
\hline & AJ 4604 & $H$ & - & \pm & - & - & - & $H$ & $H$ & $H$ & - \\
\hline & AJ 5370 & $H$ & - & + & - & - & - & H & $H$ & $H$ & - \\
\hline \multirow{3}{*}{$\begin{array}{l}\text { C. parapsilosis } \\
\text { form II } \\
\text { L. elongisporus }\end{array}$} & AJ 4571 & $H$ & - & \pm & - & - & - & $H$ & $H$ & - & - \\
\hline & AJ 4575 & $H$ & - & \pm & - & - & - & $H$ & $\ddot{H}$ & - & - \\
\hline & AJ 5470 & $H$ & - & \pm & - & - & - & $H$ & $H$ & - & - \\
\hline
\end{tabular}

a $\#$, intensive agglutination; + , weak agglutination; \pm , ambiguous; - , negative. 
absorbed with L. elongisporus, antibody factors were completely absorbed.

Antiserum for L. elongisporus AJ 5470 absorbed with C. parapsilosis form I J-1015 or C. parapsilosis form II AJ 4571 gave a result similar to the case mentioned above (Table 4). Antiserum for C. parapsilosis form I J-1015 absorbed with C. parapsilosis form II AJ 4571 or L. elongisporus AJ 5470 agglutinated the cells of C. parapsilosis form I though agglutination was not so clear in some cases, but it did not agglutinate those of $C$. parapsilosis form II and L. elongisporus. These results indicated that these two groups possessed a small amount of respectively specific antigens in addition to the large amount of antigens common to both groups.

Agglutination by factor antisera demonstrated a more clear difference between the two groups (Table 5). All the strains employed were agglutinated by factor antisera $1,5,13$, and $13 \mathrm{~b}$. Twenty strains belonging to $C$. parapsilosis form I were agglutinated also by factor antiserum 24 but $C$. parapsilosis form II and L. elongisporus were not.

When factor antiserum 24 was absorbed with heated cells of $C$. parapsilosis J-1015, agglutinins intensively reacting with $S$. rosei remained (Table 6). Therefore, antibody factors of factor antiserum 24 which agglutinate $C$. parapsilosis form I are antibodies induced by partial antigens of antigen 24 .

Gel diffusion precipitation reaction of antisera for representative strains of C. parapsilosis form I and form II, and L. elongisporus against alkali-extracted polysaccharides of these yeasts is shown in Fig. 1. These polysaccharides were composed of only D-mannose.

Table 6. Specificity of factor antiserum 24 prepared from antiserum for Saccharomyces rosei.

\begin{tabular}{|c|c|c|c|c|c|c|c|c|c|c|c|c|c|}
\hline \multirow[b]{2}{*}{$\begin{array}{l}\text { Antiserum } \\
\text { for }\end{array}$} & \multirow[b]{2}{*}{$\begin{array}{l}\text { Absorbed } \\
\text { with }\end{array}$} & \multicolumn{12}{|c|}{ Antigens } \\
\hline & & 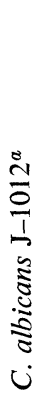 & 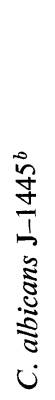 & 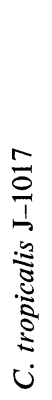 & $\begin{array}{l}0 \\
0 \\
0 \\
1 \\
0 \\
0 \\
0 \\
0 \\
0 \\
0 \\
0 \\
0 \\
0 \\
0 \\
0 \\
0\end{array}$ & 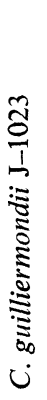 & 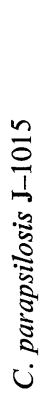 & 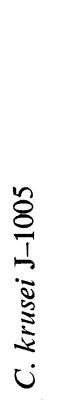 & 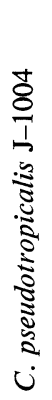 & 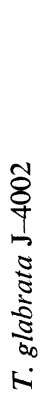 & 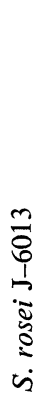 & 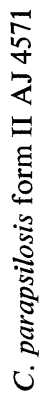 & 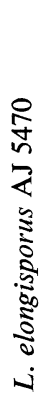 \\
\hline $\begin{array}{l}\text { S. rosei J-6013 } \\
\text { (IFO 0428) }\end{array}$ & C. albicans $\mathrm{J}-1012^{a}$ & - & - & - & - & - & $H$ & - & - & - & 册 & - & - \\
\hline$n$ & $\begin{array}{l}\text { C. albicans } \mathrm{J}-1012^{a} \\
+ \text { C. parapsilosis } \\
\quad \mathrm{J}-1015\end{array}$ & - & - & - & - & - & - & - & - & - & H & - & - \\
\hline
\end{tabular}

a Serotype_A.

$b$ Serotype B. 


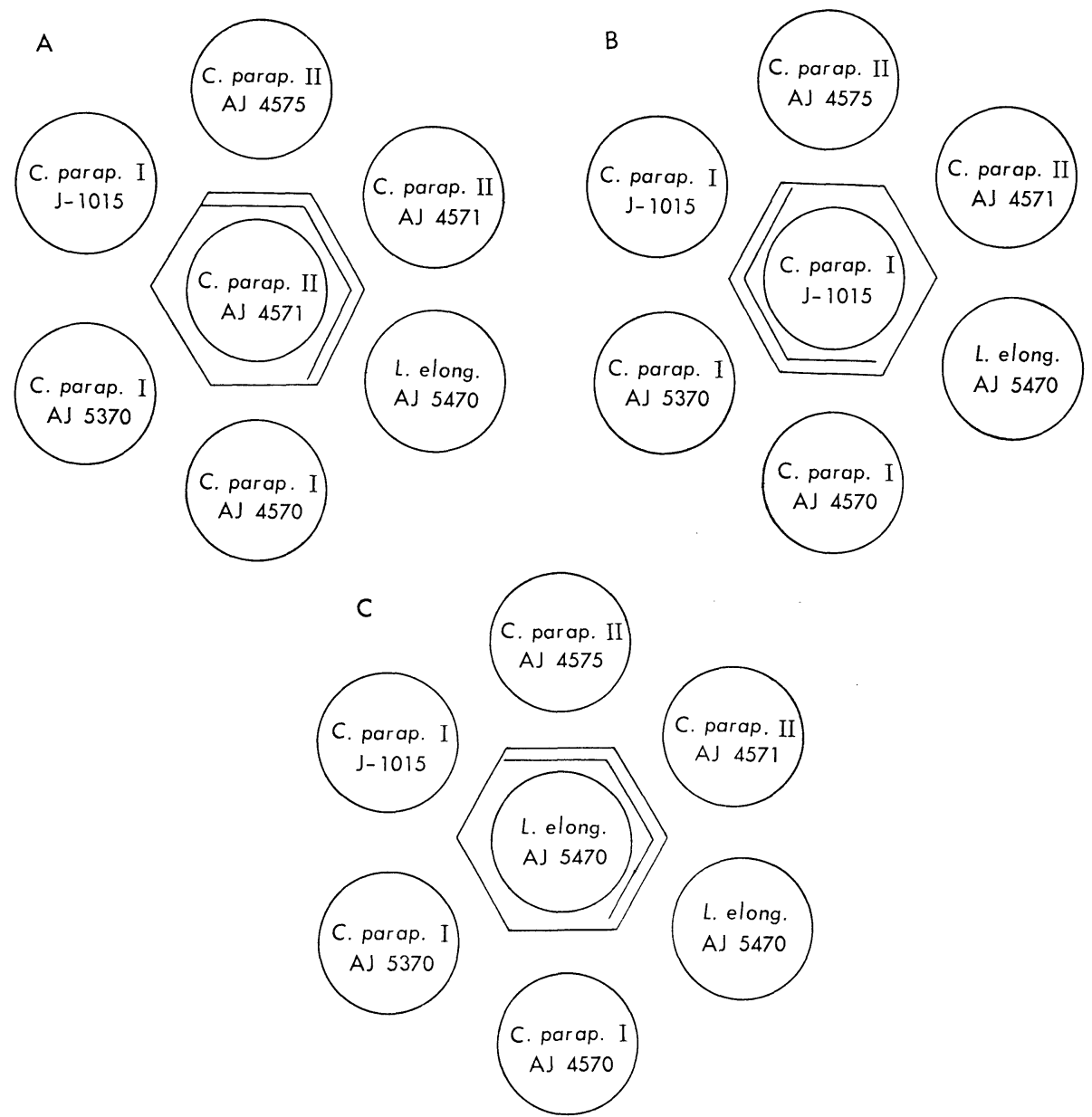

Fig. 1. Schematic illustrations of agar gel diffusion precipitation with mannans from $C$. parapsilosis and L. elongisporus.

A, antiserum for C. parapsilosis form II AJ 4571 was placed in the central well; B, antiserum for $C$. parapsilosis form I J-1015 was placed in the central well; C, antiserum for L. elongisporus AJ 5470 was placed in the central well.

Antigens were placed in the peripheral well in each case.

When antiserum for $C$. parapsilosis form II AJ 4571 was placed in the central well, a clear precipitation line common to mannans of $C$. parapsilosis form I, form II, and L. elongisporus was formed against each of mannans placed in the peripheral wells (Fig. 1A). In addition to the precipitation line mentioned above, a weak line was formed against each of mannans from $C$. parapsilosis form II and $L$. elongisporus. The latter was not observed in the case of mannans from C. parapsilosis form I. 


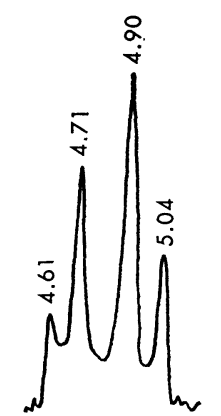

C. parapsilosis form I AJ 4570

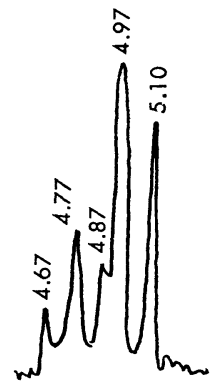

C. parapsilosis form II AJ 4571

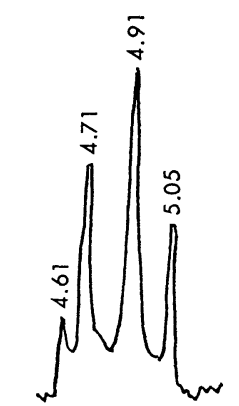

C. parapsilosis form I AJ 5370

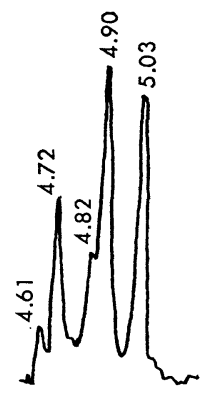

C. parapsilosis form II AJ 4575

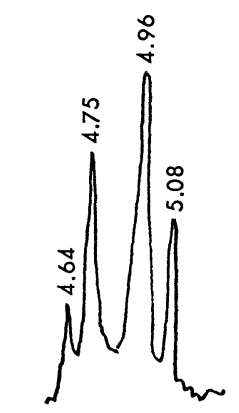

C. parapsilosis form I J-1015

L. elongisporus AJ 5470

Fig. 2. Proton NMR spectra (H-1 region) of mannans from $C$. parapsilosis and L. elongisporus.

Arabic numerals indicate $\tau$ values.

When antiserum for L. elongisporus AJ 5470 was employed, similar results were obtained (Fig. 1C).

When antiserum for $C$. parapsilosis form I J-1015 was used, two kinds of precipitation line formed (Fig. 1B). The one was common to mannans from C. parapsilosis form I, form II, and L. elongisporus. The other was formed against mannans from $C$. parapsilosis form I but not against $C$. parapsilosis form II or L. elongisporus.

Proton NMR spectra of alkali-extracted mannans from six representative strains are shown in Fig. 2. All of the mannans tested demonstrated four signals with similar $\tau$ values in the range of $\mathrm{H}-1$ region (Fig. 2). Differences were found, however, in the intensity of signals with $\tau$ values of 4.71-4.77 and 5.03-5.10. Namely, the signal of $\tau$ 4.71-4.77 was more intensive than that of $\tau$ 5.03-5.10 in mannans from C. parapsilosis form I (AJ 4570, AJ 5370, and J-1015), while the latter was more intensive than the former in the case of $C$. parapsilosis form II 
(AJ 4571 and AJ 4575) and L. elongisporus (AJ 5470). An additional minor signal with $\tau$ value of 4.82-4.86 was observed in mannans from $C$. parapsilosis form II and L. elongisporus though it was not clearly detected except for L. elongisporus (Fig. 2).

\section{DISCUSSION}

In 1952, ReCCA and MrAK (II) isolated a yeast forming long oval ascospores from orange concentrate, and described it as a new species of the genus Saccharomyces, S. elongasporus RECCA et MRAK. VAN DER WALT (12) eliminated this yeast from Saccharomyces and established a new genus Lodderomyces by the reason of the formation of long oval ascospores. He considered that L. elongasporus was the perfect form of $C$. parapsilosis because $L$. elongasporus agreed sufficiently closely with $C$. parapsilosis morphologically and physiologically with the exception of its ability to form ascospores.

In the Second Edition of "The Yeasts, a Taxonomic Study" published in 1970, the genus Lodderomyces was adopted but specific epithet of L. elongasporus, the only species of the genus, was corrected as "elongisporus." This yeast was regarded as the perfect form of C. parapsilosis yet. In 1971, however, MEYER and PHAFF (4) reported that DNAs of this proposed pair of yeasts were not closely related in DNA-DNA hybridization experiment though guanine+cytosine ratios were similar. This result clearly indicated that L. elongisporus and C. parapsilosis were not closely related and that the former was not the perfect form of the latter. These two species, however, closely resemble each other in taxonomic criteria commonly employed. Therefore, imperfect form of L. elongisporus freshly isolated from natural sources is difficult to be distinguished from $C$. parapsilosis unless DNA homology study is carried out. In the present experiment, we found that L. elongisporus including its imperfect form could be discriminated from $C$. parapsilosis in serological characteristics, proton NMR spectrum of alkali-extracted mannans, lack of assimilation of L-arabinose, requirement of thiamine, and in the excretion of excess amount of riboflavin into synthetic media. Reciprocal absorption experiments of antisera and subsequent agglutination experiment showed that cell surface antigens of these two species differed from each other though the difference is not so distinct in some cases (Table 4). A clear difference was found in agglutination against factor antiserum 24 prepared from antiserum for Saccharomyces rosei and gel diffusion precipitation of mannans (Table 5, Fig. 1). Factor antiserum 24 agglutinated the cells of $C$. parapsilosis form I but neither those of $C$. parapsilosis form II nor L. elongisporus (Table 5). Serological investigations clearly demonstrated that these two species have respectively specific antigens in addition to antigens common to both species.

Gel diffusion precipitation reaction (Fig. 1) and proton NMR spectrum (Fig. 2) of alkali-extracted mannans indicated that the chemical structure of 
the cell wall mannan, a cell wall component usually responsible for specificity of antigens of yeast species, is different in these two species.

In the present experiment, all of the strains belonging to $C$. parapsilosis form I rapidly assimilated L-arabinose, while those of $C$. parapsilosis form II and $L$. elongisporus did not (Table 2). According to the standard description of $C$. parapsilosis in the Second Edition of "The Yeasts, a Taxonomic Study" (13), assimilation of L-arabinose is positive or negative. Strains having the latter property are assumed to belong to the imperfect form of L. elongisporus. $C$. parapsilosis var. querci (14) also does not assimilate L-arabinose. This variety was not included in the present investigation.

C. parapsilosis form II and L. elongisporus required thiamine in addition to biotin but $C$. parapsilosis form I does not require thiamine (Table 3). Excess amount of riboflavin was excreted and turned the color of the media yellow after 1 to 3 weeks of cultivation when $C$. parapsilosis form II and L. elongisporus were grown in the synthetic media employed for the carbon assimilation test (Table 3). This phenomenon was not observed in the case of $C$. parapsilosis form I.

As mentioned above, $C$. parapsilosis and $L$. elongisporus are distinct species without any close relationship, as clearly demonstrated by MEYER and PHAFF (4) in DNA-DNA hybridization study, in spite of a close resemblance in taxonomic criteria commonly employed $(3,12)$ and similar guanine + cytosine content in DNA $(4,15)$. Strains tentatively dealt with as $C$. parapsilosis form II by the present author (2) represent the imperfect form of L. elongisporus. Negative assimilation of L-arabinose, requirement of thiamine, and excretion of excess amount of riboflavin are useful for practical discrimination of the imperfect form of $L$. elongisporus from $C$. parapsilosis, and agglutination test with factor antiserum 24 and use of proton NMR spectrum of mannan are considered to be more practical than DNA-DNA hybridization study for routine identification.

The authors express their thanks to Miss A. Nishikawa for her help in determination of proton NMR spectrum.

\section{REFERENCES}

1) K. Komagata, T. Nakase, and N. Katsuya, J. Gen. Appl. Microbiol,, 10, 323 (1964).

2) T. NaKase, Nihon Saikingaku Zasshi, 29, 611 (1974).

3) J. P. van Walt, In The Yeasts, a Taxonomic Study, ed. by J. LodDER, North-Holland Publ. Co., Amsterdam p. 403 (1970).

4) S. A. Meyer and H. J. Phaff, Proc. Ist Spec. Int. Symp. Yeasts, Smolenice, 1971, p. 375 (1973).

5) L. J. Wickerham, Taxonomy of Yeasts, U.S.D.A. Technical Bulletin No. 1029 (1951).

6) J. P. van der Walt, In The Yeasts, a Taxonomic Study, ed. by J. Lodder, North-Holland Publ. Co., Amsterdam, p. 34 (1970).

7) K. Komagata and T. NAKASE, Shokuhin Eiseigaku Zasshi, 8, 53 (1967).

8) P. A. J. Gorin and J. F. T. Spencer, Can. J. Chem., 46, 2299 (1968). 
9) T. Tsuchiya, Y. Fukazawa, and S. Kawakita, Mycopathol. Mycol. Appl., 10, 191 (1959).

10) O. Ouchterloni, Gel-diffusion techniques, In Immunological Methods, ed. by J. F. ACKroyed, Blackwell Scientific Publ., Oxford (1964).

11) J. ReCCA and E. M. MraK, Food Technol., 6, 450 (1952).

12) J. P. van Der Walt, Antonie van Leeuwenhoek J. Microbiol. Serol., 32, 1 (1966).

13) N. van Uden and H. Buckley, In The Yeasts, a Taxonomic Study, ed. by J. Lodder, North-Holland Publ. Co., Amsterdam, p. 893 (1970).

14) N. van Uden and L. Do Carmo-Sousa, Port. Acta Biol. (B), 6, 239 (1959).

15) T. NaKase and K. Komagata, J. Gen. Appl. Microbiol., 17, 259 (1971).

16) K. Fukushima, T. Nakase, and K. Komagata, Nihon Suisan Gakkai-shi, 33, 763 (1967). 